\title{
Well Defined Precision Ethylene/Vinyl Fluoride Polymers: Synthesis and Crystalline Properties
}

\author{
Emine Boz, Alexander J. Nemeth, and Kenneth B. Wagener* \\ The George and Josephine Butler Polymer Research Laboratory and Center for \\ Macromolecular Science and Engineering, University of Florida, Department \\ of Chemistry, Gainesville, Florida 32611-7200. \\ Keesu Jeon, Robert Smith, Farhod Nazirov, Rufina G. Alamo* \\ FAMU/FSU College of Engineering, Department of Chemical and Biomedical \\ Engineering, Tallahassee, Florida, 32310-6046. \\ Michael R. Bockstaller \\ Department of Materials Science and Engineering, Carnegie Mellon \\ University, Pittsburgh, Pennsylvania, 15213
}




\section{Gel Permeation Chromatography.}

File: JAO25A0789 \#1_BAUGH_33PEVF_HIGH MW Inst: 025 $\mathrm{dWM} / \mathrm{dLM} 2.0 \mathrm{Mz}=17214 ; \mathrm{Mw}=8898 ; \mathrm{Mn}=4464$

21:29:01 18Dec2006

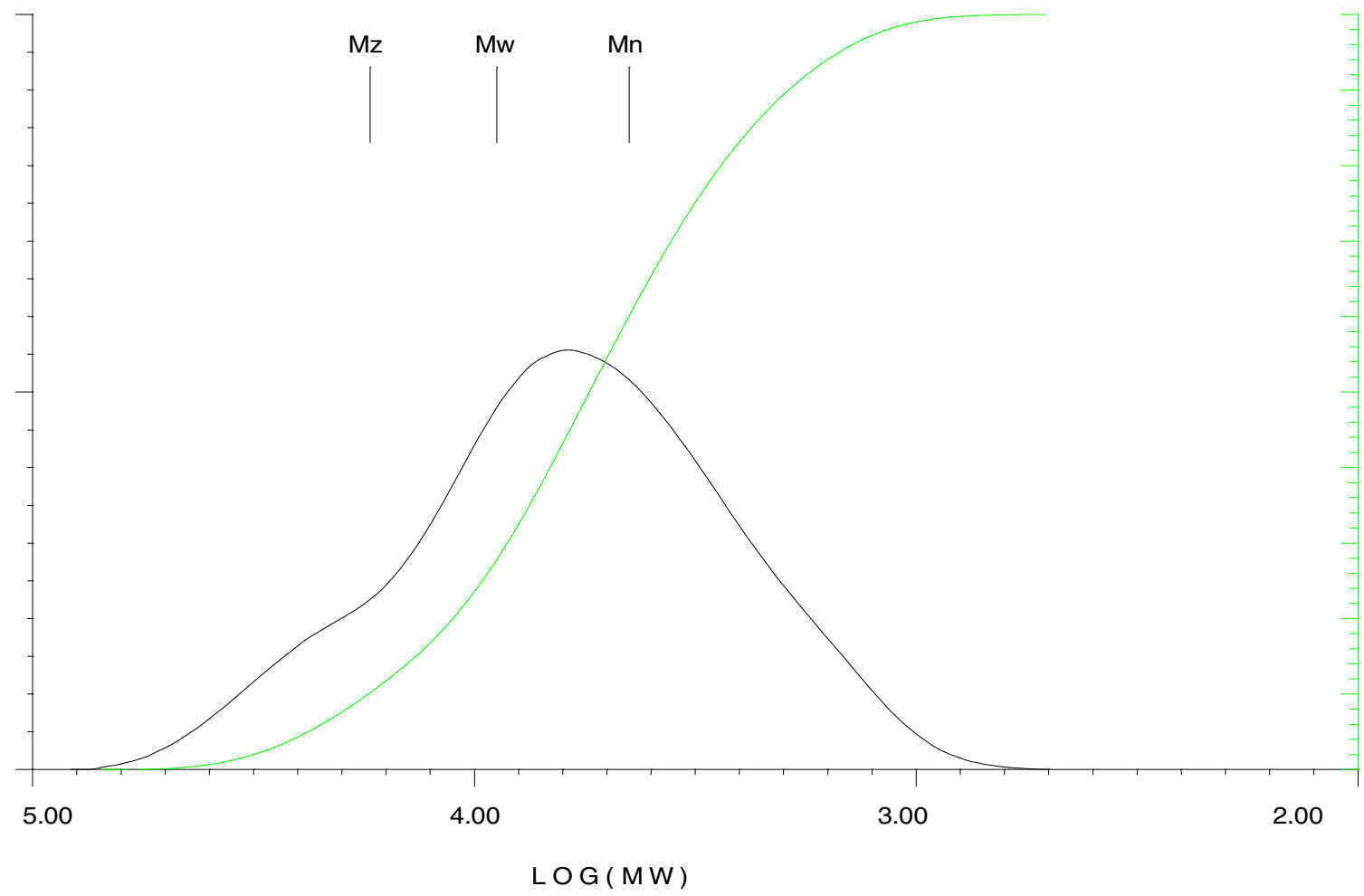

Figure S1. SEC trace for PE9F. 
File: JAO25A0790 \#2_BAUGH_66PEVF Inst: 025
dWM/dLM 2.0 Mz $=18071 ; \mathrm{Mw}=10424 ; \mathrm{Mn}=4663$

23:47:01 18Dec2006
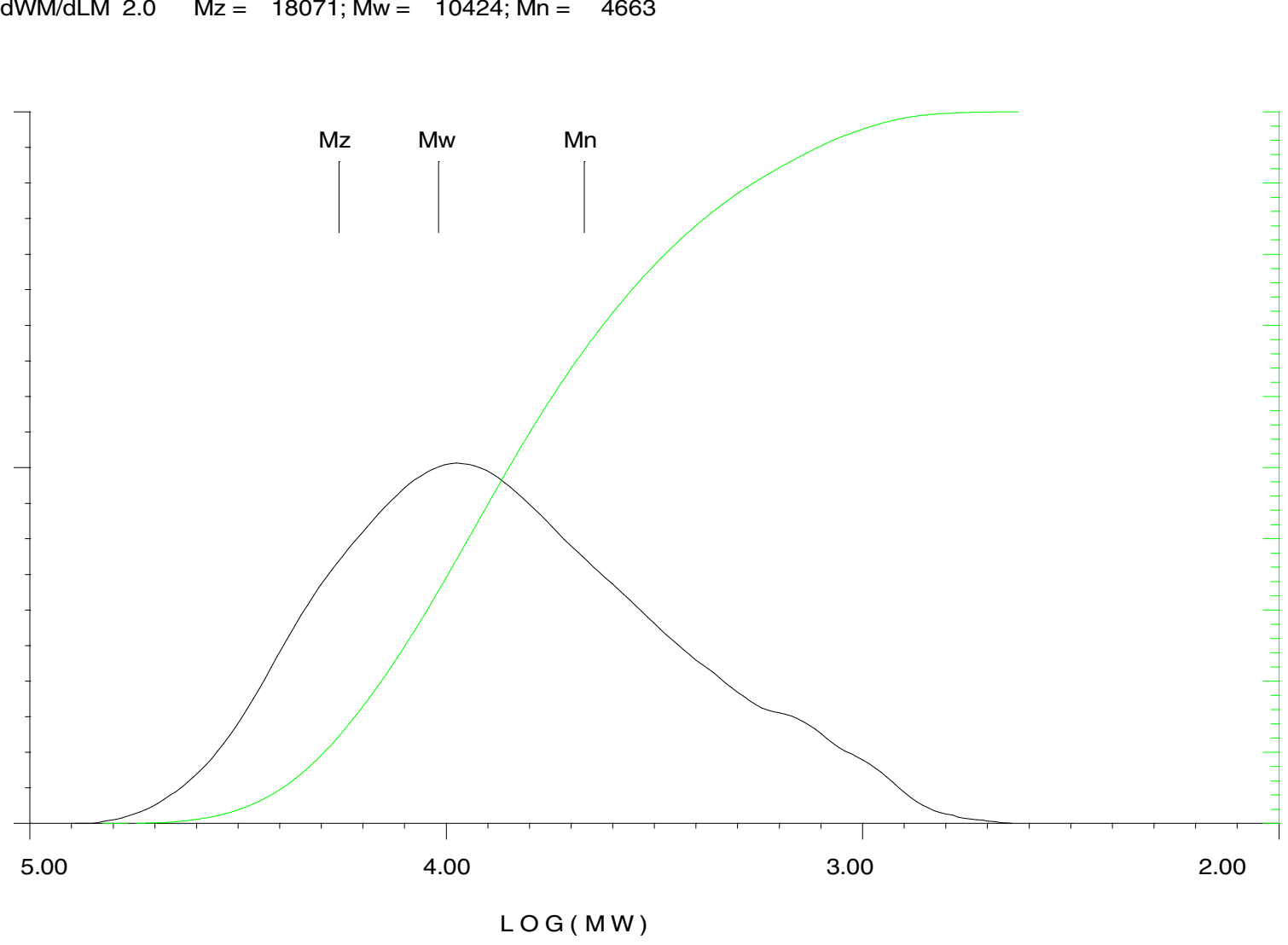

Figure S2. SEC trace for PE15F. 
File: JAO25A0791 \#3_BAUGH_99PEVF_HIGH MW Inst: $025 \quad$ 2:05:02 19Dec2006 $\mathrm{dWM} / \mathrm{dLM} 2.0 \mathrm{Mz}=13517 ; \mathrm{Mw}=7629 ; \mathrm{Mn}=4235$

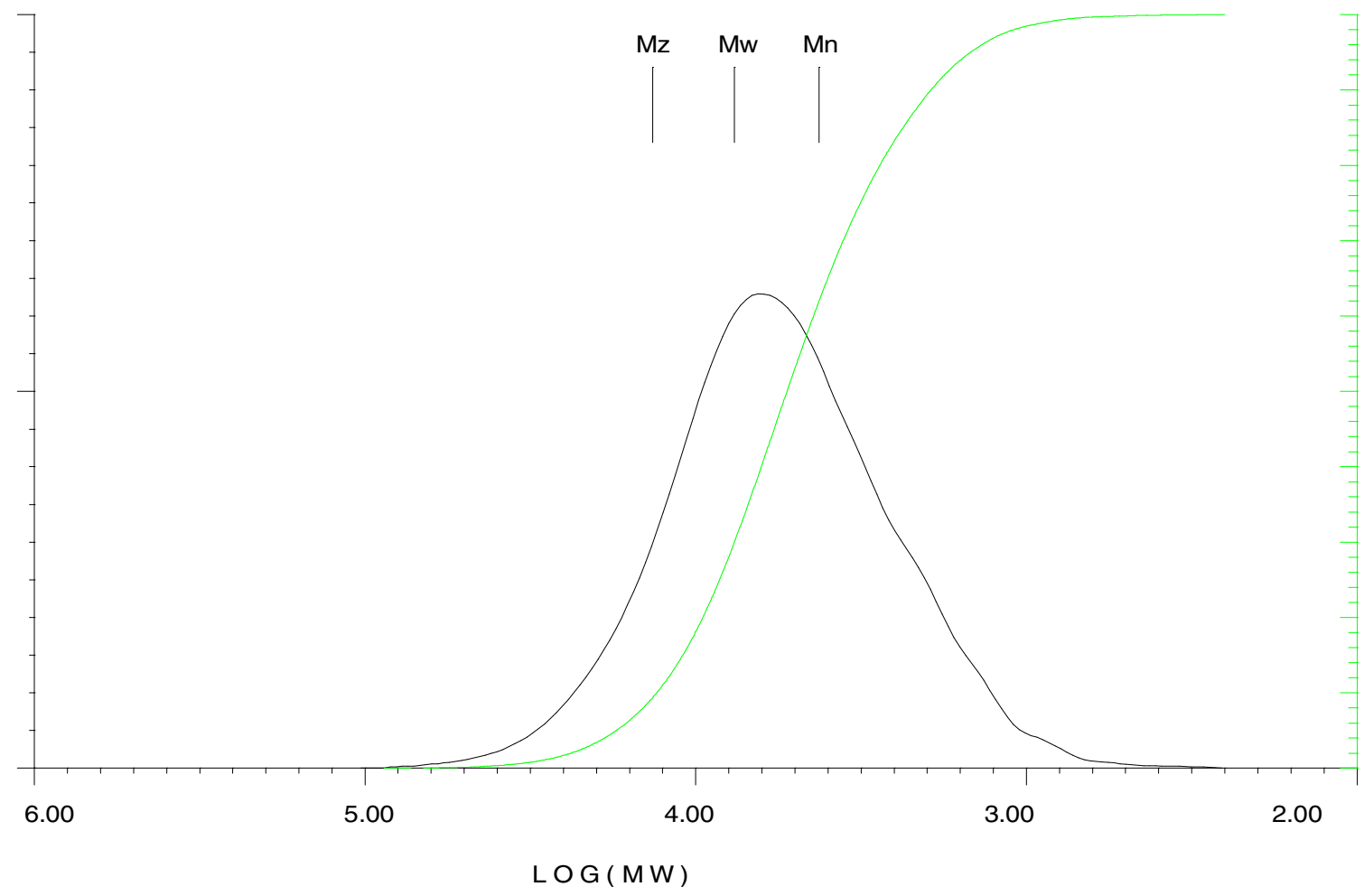

Figure S3. SEC trace for PE21F. 


\section{Crystalline Morphology.}

The lamellar morphology of PE21F and PE15F was investigated using non-contact atomic force microscopy (AFM). The samples ( $\sim 50 \mu \mathrm{m}$ thick films) were slowly cooled at 1 ${ }^{\circ} \mathrm{C} / \mathrm{min}$ from the melt to room temperature on a Linkam hot stage. In Figure S4, PE21F shows many long stacked lamellae. For PE15F the number of stacked lamellae decreases compared with PE21F and are observed as flat-on lamellae.
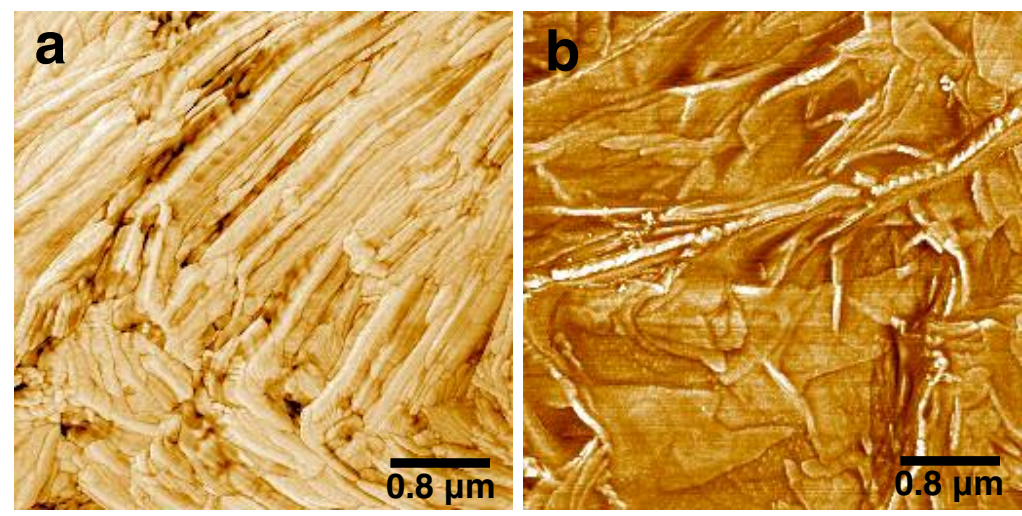

Figure S4. AFM phase images for (a) PE21F and (b) PE15F slowly cooled $\left(1^{\circ} \mathrm{C} / \mathrm{min}\right)$ from the melt to room temperature. 